\title{
DISTRIBUTION, ORIGIN, AND FINE STRUCTURES OF CHOLECYSTOKININ-8-LIKE IMMUNOREACTIVE TERMINALS IN THE NUCLEUS VENTROMEDIALIS HYPOTHALAMI OF THE RAT
}

\author{
SHINOBU INAGAKI,*, ${ }^{*}$ YAHE SHIOTANI, ${ }^{*}$ MARIKO YAMANO, ${ }^{*}$ SADAO SHIOSAKA, ${ }^{*}$ \\ HIROSHI TAKAGI,* KAYOKO TATEISII, $\ddagger$ ETSUO HASHIMURA,§ TOSHIYUKI HAMAOKA, $\ddagger$ AND \\ MASAYA TOHYAMA*
}

* Department of Neuroanatomy, Institute of Higher Nervous Activity, Osaka University Medical School, Osaka (530), $\ddagger$ Department of Oncogenesis, Institute for Cancer Research, Osaka University Medical School, 1-1-50, Fukushima, Fukushimaku, Osaka (553), and § Research and Development Division, Otsuka Assay Laboratories, Otsuka Pharmaceutical Company, Ltd., Tokushima (771-01), Japan

Received August 22, 1983; Revised November 1, 1983; Accepted November 23, 1983

\begin{abstract}
The distribution, origin, and fine structures of cholecystokinin-8-like immunoreactive (CCKI) fibers in the nucleus ventromedialis hypothalami $(\mathrm{vm})$ of the rat were examined using immunohistochemistry.

CCKI fibers were moderately concentrated in the ventrolateral part of the vm, decreasing in number dorsomedially. However, no CCKI cells were seen in the vm even in colchicine-treated rats. In addition, the destruction of the lateral part of the nucleus parabrachialis dorsalis (pbd) where numerous CCKI cells were seen resulted in a marked decrease in CCKI fibers in the vm on the operated side.

Electron microscopic observations revealed that CCKI terminals make synaptic contact with soma, spine, and the proximal segment of the dendrite. The neurons making synaptic contact with the CCKI fibers had moderately electron-lucent cytoplasm.

These findings suggest that the CCKI fibers in the vm originate from CCKI cells in the lateral part of the pbd and directly influence the vm neurons.
\end{abstract}

The nucleus ventromedialis hypothalami $(\mathrm{vm})$ has been shown to play a role in a variety of functions such as emotional and feeding behaviours (Hobel and Teitebaum, 1962; Brobeck, 1964; Palka and Sawer, 1966; Bernardi and Skelton, 1967; Mayer and Thomas, 1967; Stevenson, 1969; Palka et al., 1971; Carrer et al., 1973/74; Grossman, 1975; Nance, 1976; Novin et al., 1976; Oomura, 1976), endocrine activity (Hinman and Griffith, 1973; Martin, 1973; Bray and Campfield, 1975), autonomic system (Ridley and Brooks, 1965; Bernardi and Frohman, 1971), and reproduction (Kennedy, 1963). Recently, immunohistochemical studies have demonstrated the presence of cholecystokinin (CCK)-8 fibers in the vm (Hökfelt et al., 1978; Innis et al., 1979; Lorén et al., 1979; Vanderhaeghen et al., 1980; Cho et al., 1983) in addition to other kinds of peptides (Hökfelt et al., 1978).

CCK-8 was first identified in the brain as a gastrinlike peptide by Vanderhaeghen et al. (1975). Subsequent

\footnotetext{
${ }^{1}$ To whom correspondence should be addressed.
}

studies demonstrated that this immunoreactivity is mainly caused by the presence of $\mathrm{COOH}$-terminal octapeptides of CCK, which shared the same $\mathrm{COOH}$-terminal five amino acids with gastrin (Muller et al., 1967; Dockray, 1976; Dockray et al., 1978; Rehfeld, 1977, 1978a, b, 1980; Rehfeld and Goltermann, 1979; Rehfeld et al., 1979). Accumulating evidence suggests that CCK functions as a neurotransmitter or ncuromodulator (Dockray, 1976; Rehfeld, 1977, 1978a, b, 1980; Vandesande et al., 1977; Hökfelt et al., 1978, 1980a, b; Innis et al., 1979; Larsson and Rehfeld, 1979; Lorén et al., 1979; Emson et al., 1980; Greenwood et al., 1981; Meyer et al., 1981; Beinfeld and Palkovits, 1982; Cho et al., 1983; Kiyama et al., 1983; Kubota et al., 1983). Therefore, the findings that CCK fibers are localized in the vm imply that at least some vm functions are mediated by CCK fibers in this area, although the precise transmission mechanisms are quite obscure.

To provide a morphological basis for better understanding the role or transmission mechanisms of CCK 
in the vm, we have attempted to elucidate the origins and fine structures of the CCKI fibers in the vm, of which little is known.

\section{Materials and Methods}

\section{Light microscopic analysis}

A total of 85 male young rats (weighing 50 to $100 \mathrm{gm}$ ) were used in this study. Seven rats were prepared for analysis of the normal distribution of CCK-8-like immunoreactive (CCKI) structures in the brain. Three rats were given intraventricular colchicine pretreatment $(3 \mu \mathrm{l}$ at $2 \mathrm{mg} / \mathrm{ml}$ ) and killed 24 to $48 \mathrm{hr}$ after the injection. The remaining rats were divided into three groups: (1) knife cut study (28 rats), (2) retrograde tracer study using HRP (19 rats), and (3) electrolytic lesion study (28 rats). All experiments were carried out stereotaxically according to the atlas of König and Klippel (1963) under sodium pentobarbital anesthesia ( $40 \mathrm{mg} / \mathrm{kg}$, i.p.).

\section{Surgical procedures}

Knife cut study. Figure 1 illustrates the four types of hemi- or total transections of the brain: $(a)$ Just rostral to the vm (A $5660 \mu \mathrm{m}$ ) (seven rats), (b) just caudal to the vm (A $3430 \mu \mathrm{m}$ ) (six rats), (c) at the level of the decussation of the superior cerebellar peduncle (A 160 $\mu \mathrm{m})$ just rostral to the nucleus parabrachialis dorsalis (pbd) (seven rats), and ( $d$ ) just caudal to the pbd (P 2000 $\mu \mathrm{m}$ ) (Fig. 1d) (eight rats). Five to 7 days after operation the rats were processed for immunohistochemistry.

HRP study. The above results suggested that CCKI fibers in the vm originate in an area between A $160 \mu \mathrm{m}$ and P $2000 \mu \mathrm{m}$. Therefore, HRP (40\%) solution (Sigma type $\mathrm{VI}$ ) in a glass micropipette was iontophoretically injected into the vm. A high voltage constant current source was used to provide a pulse-positive alternating current ( $7 \mathrm{sec}$ on, $7 \mathrm{sec}$ off). A single injection of HRP was made stereotaxically by using a positive current of $2.5 \mu \mathrm{A}$ for $20 \mathrm{~min}$. After $48 \mathrm{hr}$ the animals were processed by the HRP method. To rule out the possibility of HRP uptake by the fibers that pass through the vm, HRP was also injected into the areas rostral and dorsal to the vm.

Lesion study. Electrolytic lesions were stereotaxically made by passing a DC current $(40 \mu \mathrm{A}$ for 3 to $7 \mathrm{~min}$ ) through a monopolar electrode placed in the lateral part of the pbd (nine rats), central gray matter (six rats), or

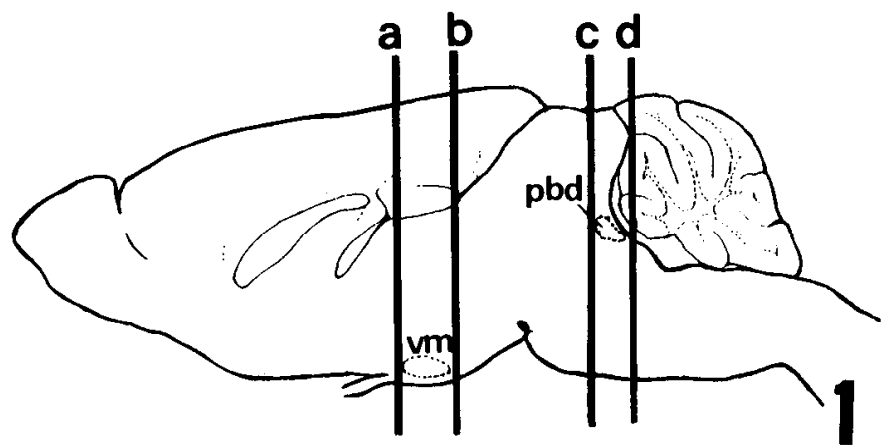

Figure 1. Schematic drawing of knife cut sites in the sagittal plane. (See the text for explanation.) inferior colliculus (six rats). As a control lesions were also made in the adjacent areas (seven rats). After 5 to 7 days the animals were processed for immunohistochemistry. The extent of lesion was carefully assessed after cresyl violet staining.

\section{Immunohistochemistry}

Preparation of tissue. All of the anesthetized rats were perfused intracardially with $50 \mathrm{ml}$ of saline followed by $200 \mathrm{ml}$ of cold Zamboni's fixative (Zamboni and De Martino, 1967). The brain was removed rapidly and immersed in the same fixative for $24 \mathrm{hr}$ and rinsed overnight in phosphate buffer containing $30 \%$ sucrose at $4^{\circ} \mathrm{C}$. Serial frontal or sagittal sections $(10 \mu \mathrm{m})$ were cut on a cryostat, paying attention to the stereotaxic levels of the brain.

Immunohistochemical procedure. The sections were immediately incubated in cold phosphate-buffered saline (PBS) for $30 \mathrm{~min}$ before being subjected to the indirect immunofluorescent technique (Coons, 1958). Serial sections were divided into three groups: one for demonstration of CCKI structures, the second for absorption control experiments, and the third for Nissl staining with cresyl violet. The rabbit antiserum against CCK diluted 1:2000 with PBS was reacted with the first group of sections for $12 \mathrm{hr}$ at $15^{\circ} \mathrm{C}$ in a humid atmosphere. The sections were rinsed first in cold PBS for $10 \mathrm{~min}$, then in PBS containing 1\% Triton $\mathrm{X}-100$ for $10 \mathrm{~min}$, and next in PBS for $10 \mathrm{~min}$. The sections were then incubated with fluorescein isothiocyanate-conjugated goat antirabbit antiserum (Miles, Co. Ltd.) diluted at 1:2000 with PBS for $12 \mathrm{hr}$ at $15^{\circ} \mathrm{C}$ followed by rinsing in PBS for 10 min, PBS containing $1 \%$ Triton $\mathrm{X}-100$ for $10 \mathrm{~min}$, and then again with PBS for $10 \mathrm{~min}$. The sections for the absorption control experiments were first incubated with antiserum against CCK which is absorbed by excessive CCK $(0.1 \mathrm{~mm})$, after which they were processed as described above. The sections were mounted in a PBSglycerine mixture $(1: 1)$.

\section{HRP method}

Two days after HRP injection, the rats were perfused with $1.25 \%$ glutaraldehyde- $0.5 \%$ paraformaldehyde in 0.1 M phosphate buffer containing $30 \%$ sucrose. Serial frontal sections $(30 \mu \mathrm{m})$ were cut on a cryostat and subjected to $3,3^{\prime}, 5,5^{\prime}$-tetramethylbenzidine reaction (Mesulam, 1978).

\section{Electron microscopic analysis}

A total of five rats were used in this study.

Preparation of tissue. A recently developed procedure for immuno-electron microscopic analysis by Somogyi and Takagi (1982) was used. The anesthetized rats were perfused transcardially with $25 \mathrm{ml}$ of cold saline followed by $300 \mathrm{ml}$ of cold picric acid $(0.2 \%)$-paraformaldehyde (4\%)-glutaraldehyde $(0.05 \%)$ fixative in $0.1 \mathrm{M}$ phosphate buffer ( $\mathrm{pH} 7.4)$. The brain was removed and immersed in the same fixative for $2 \mathrm{hr}$ at $4^{\circ} \mathrm{C}$. The brain including the vm was cut into small blocks (approximately $4 \times 4$ $\times 6 \mathrm{~mm}$ ) and washed three times in $0.1 \mathrm{M}$ phosphate buffer ( $\mathrm{pH} 7.4$ ) followed by $10 \%$ and $20 \%$ sucrose dis- 
solved in the same buffer until the block sank. They were then frozen in liquid nitrogen and thawed in $0.1 \mathrm{M}$ phosphate buffer at $15^{\circ} \mathrm{C}$. Section $(50 \mu \mathrm{m})$ were cut on a Vibratome (Oxford Instruments) and immersed overnight at $4^{\circ} \mathrm{C}$ in $0.1 \mathrm{M}$ phosphate buffer ( $\mathrm{pH} 7.4$ ).

Immunohistochemical procedure. For demonstration of CCKI structures, the peroxidase-antiperoxidase (PAP) method (Sternberger et al., 1970) was used. The sections were incubated with $20 \%$ normal goat serum for $30 \mathrm{~min}$ at $15^{\circ} \mathrm{C}$, washed in PBS for $1 \mathrm{hr}$ at $4^{\circ} \mathrm{C}$, and incubated with antiserum against CCK for $12 \mathrm{hr}$ at $4^{\circ} \mathrm{C}$ at a dilution of $1: 2000$ with PBS. Next they were washed three times for 40 min each with $\mathrm{PBS}$ at $4^{\circ} \mathrm{C}$, incubated with goat anti-rabbit IgG (Hoechst) at a dilution of 1:100 overnight at $15^{\circ} \mathrm{C}$, washed three times with PBS for 40 min each at $4^{\circ} \mathrm{C}$, incubated with rabbit peroxidase-antiperoxidase complex (DAKO) at a dilution of $1: 200$ for $4 \mathrm{hr}$ at $15^{\circ} \mathrm{C}$, and washed three times with PBS for 40 min each. The sections were then pre-incubated for $20 \mathrm{~min}$ in $0.05 \%$ $3,3^{\prime}$-diaminobenzidine tetra $\mathrm{HCl}$ (Sigma) dissolved in $0.05 \mathrm{M}$ Tris-HCl buffer, $\mathrm{pH}$ 7.4, followed by a reaction for $5 \mathrm{~min}$ in the same solution containing $0.01 \%$ hydrogen peroxide. After washing, the sections were postfixed for $1 \mathrm{hr}$ in $1 \% \mathrm{OsO}_{4}$ in $0.1 \mathrm{M}$ phosphate buffer $(\mathrm{pH} \mathrm{7.4)}$ and dehydrated. To enhance contrast for electron microscopy, the sections were stained with $1 \%$ uranyl acetate in a $70 \%$ alcohol dehydrated state. The sections were flat-embedded on slides in Epon 812 (Somogyi et al., 1982). Ultrathin sections were examined with or without lead staining with a Hitachi HU-12 electron microscope.

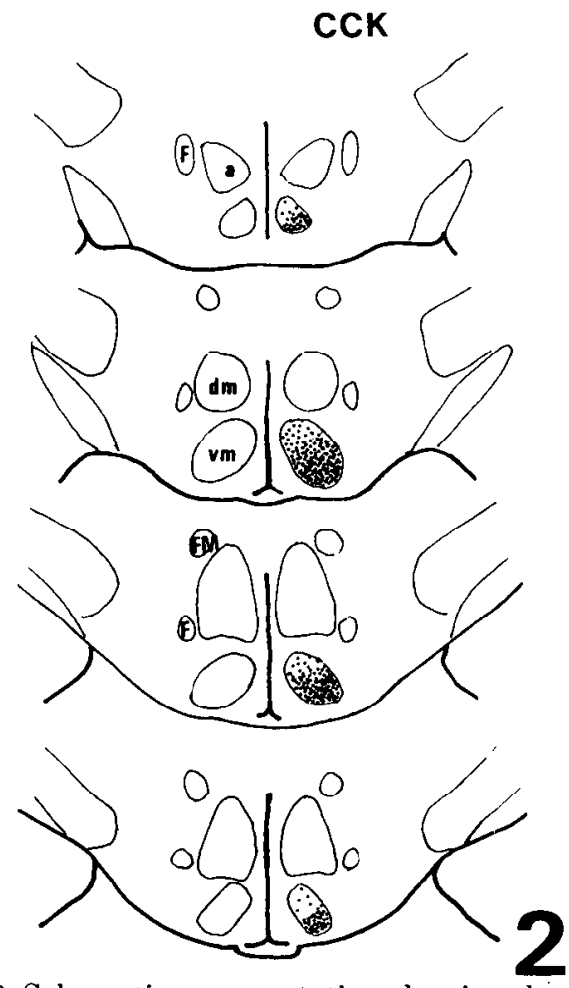

Figure 2. Schematic representation showing the distribution of CCKI fibers in the vm arranged from rostral to caudal. Small dots indicate CCKI fibers-frontal plane. CCKI fibers were moderately concentrated in the ventrolateral portion. $a$, nucleus hypothalamus anterior; $d m$, nucleus dorsomedialis hypothalami; $F$, fornix; $F M$, fasciculus mammillothalamicus.
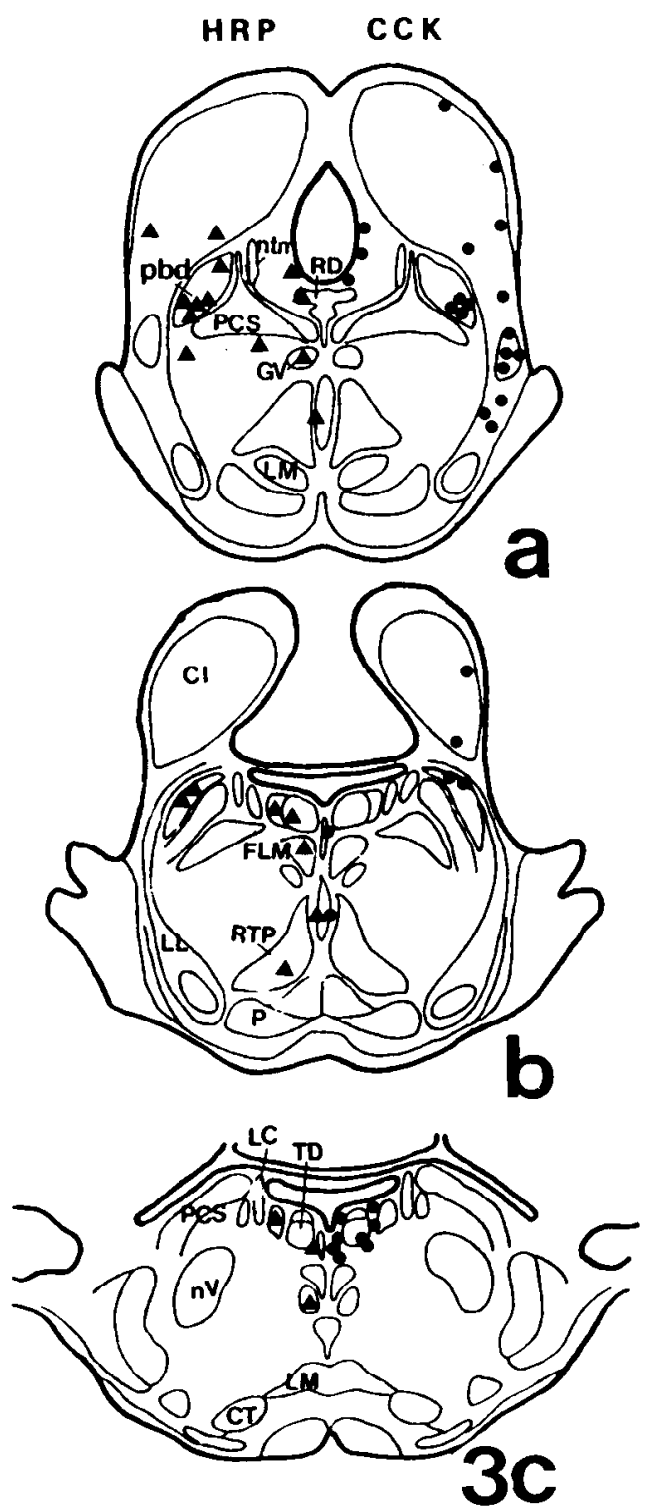

Figure 3. Schematic representation of CCKI cells in the area between A 160 and P $2000 \mu \mathrm{m}$, and HRP-labeled cells in the same area after injection of HRP into the vm. Circles indicate the location of CCKI cells and triangles the HRP-labeled cells. $C I$, inferior colliculus; $C T$, nucleus corporis trapezoidei; $F L M$, fasciculus longitudinalis medialis; $G V$, nucleus tergmenti ventralis (Gudden); $L C$, locus ceruleus; $L L$, lemniscus lateralis; $L M$, lemniscus medialis; $n t m$, nucleus tractus mesencephali nervi trigemini; $n V$, nucleus originis nervi trigemini; $P$, nucleus pontis; PCS, pedunculus cerebellaris superior; $R T P$, nucleus reticularis tegmenti pontis; $R D$, nucleus raphe dorsalis; $T D$, nucleus tegmenti dorsalis (Gudden).

\section{Antiserum against $\mathrm{CCK}$}

New Zealand white rabbits were immunized with CCK8 peptide, conjugated, and coupled with keyhole limpet hymocyanin as previously described (Hashimura et al., 1982). The specificity of the antiserum was tested using radioimmunoassay and an absorption test. Radioimmunoassay confirmed that the cross-reactivity of this antiserum with CCK-33, CCK-39, tetragastrin, and gastrin 17 was less than $40 \%$; no cross-reactivity was seen with other peptides, such as somatostatin, neurotensin, sub- 

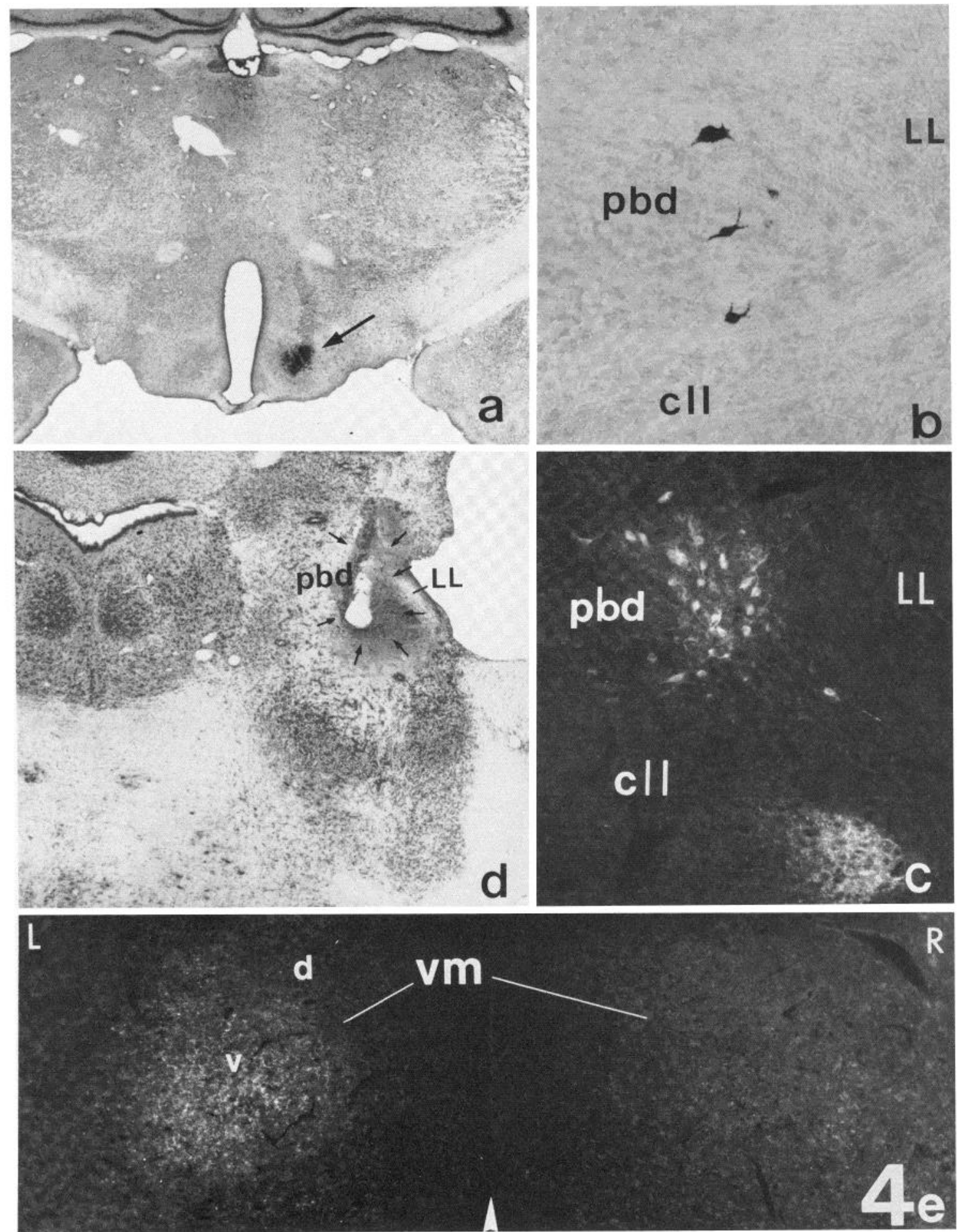

Figure 4. a, Brightfield micrograph showing the HRP injection site (arrow); case PB 51-frontal section. Magnification $\times 12$. $b$, Brightfield micrograph showing the HRP-labeled cells in the lateral part of the pbd after injection of HRP into the vm; the same case-frontal section. Magnification $\times 160$. cll, commissure of the lemniscus lateralis $(L L)$ of Probst. $c$, Fluorescent photomicrograph showing CCKI cells in the lateral part of the pbd in the colchicine-pretreated rats; case PB 6-frontal section. Magnification $\times 90$. $d$, Brightfield micrograph showing the electrolytic lesion of the lateral part of the pbd (arrows); case PB 19-frontal section. Magnification $\times 20$. e, Fluorescent photomontage showing the change in CCKI fibers in the vm after destruction of the lateral part of the pbd. This is the same case. The arrowhead indicates the third ventricle. CCKI fibers are concentrated on the control side $(L)$ in the ventrolateral part $(v)$ but are markedly reduced on the operated side $(R)-$ frontal section. $d$, dorsal part of the vm. Magnification $\times 130$. 

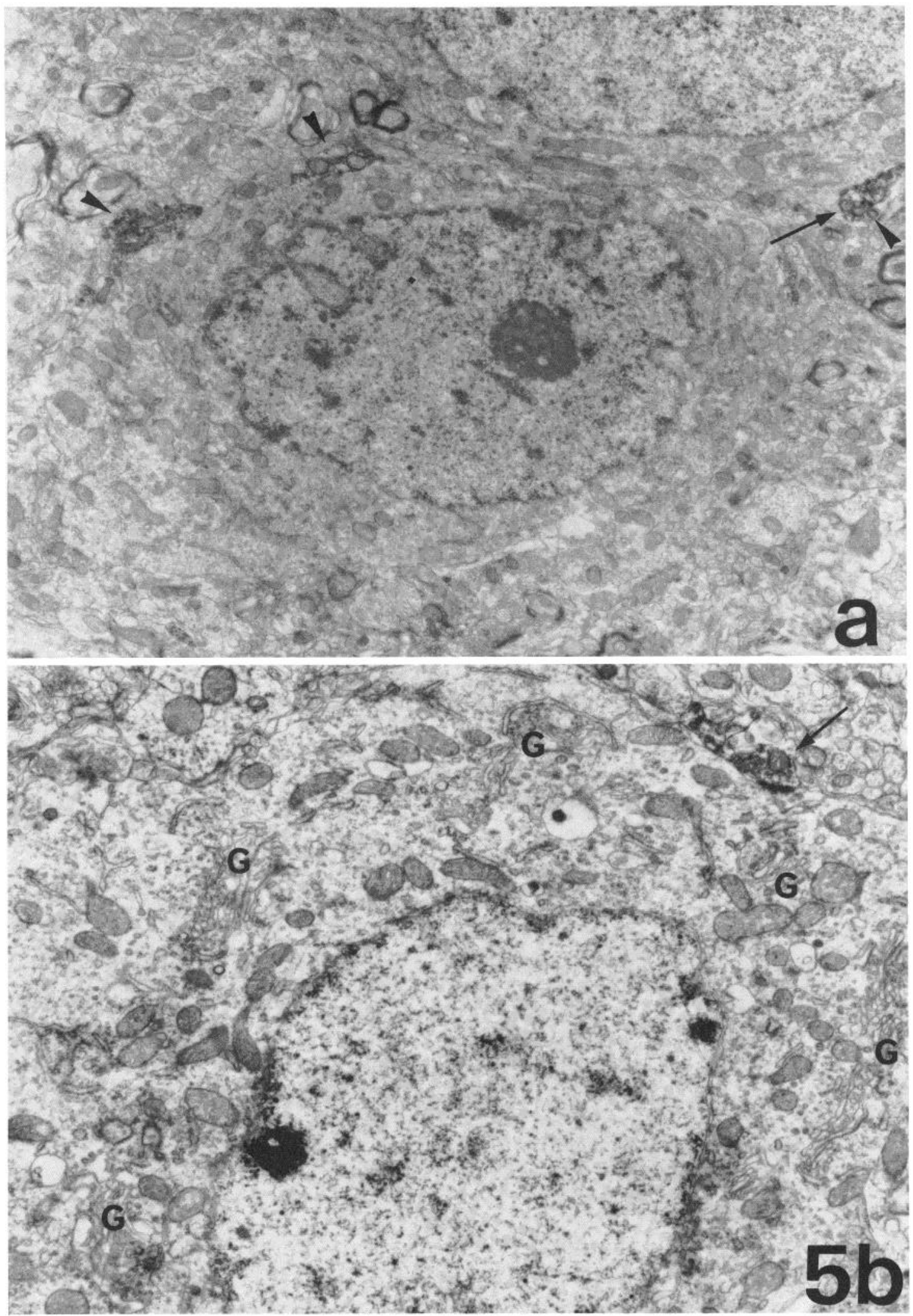

Figure 5. Low-power electron micrographs showing vm cell types with which CCKI terminals (a, arrowheads; $b$, arrow) make contact. Note relatively electron-lucent cytoplasm with well developed Golgi $(G)$ apparatus, large nucleus of the soma, and nuclear membrane invagination; without lead staining. The CCKI terminals shown by the arrow are also shown in Figures 6 and $7 a$ at higher magnification. Magnification $\times 12,000$. 


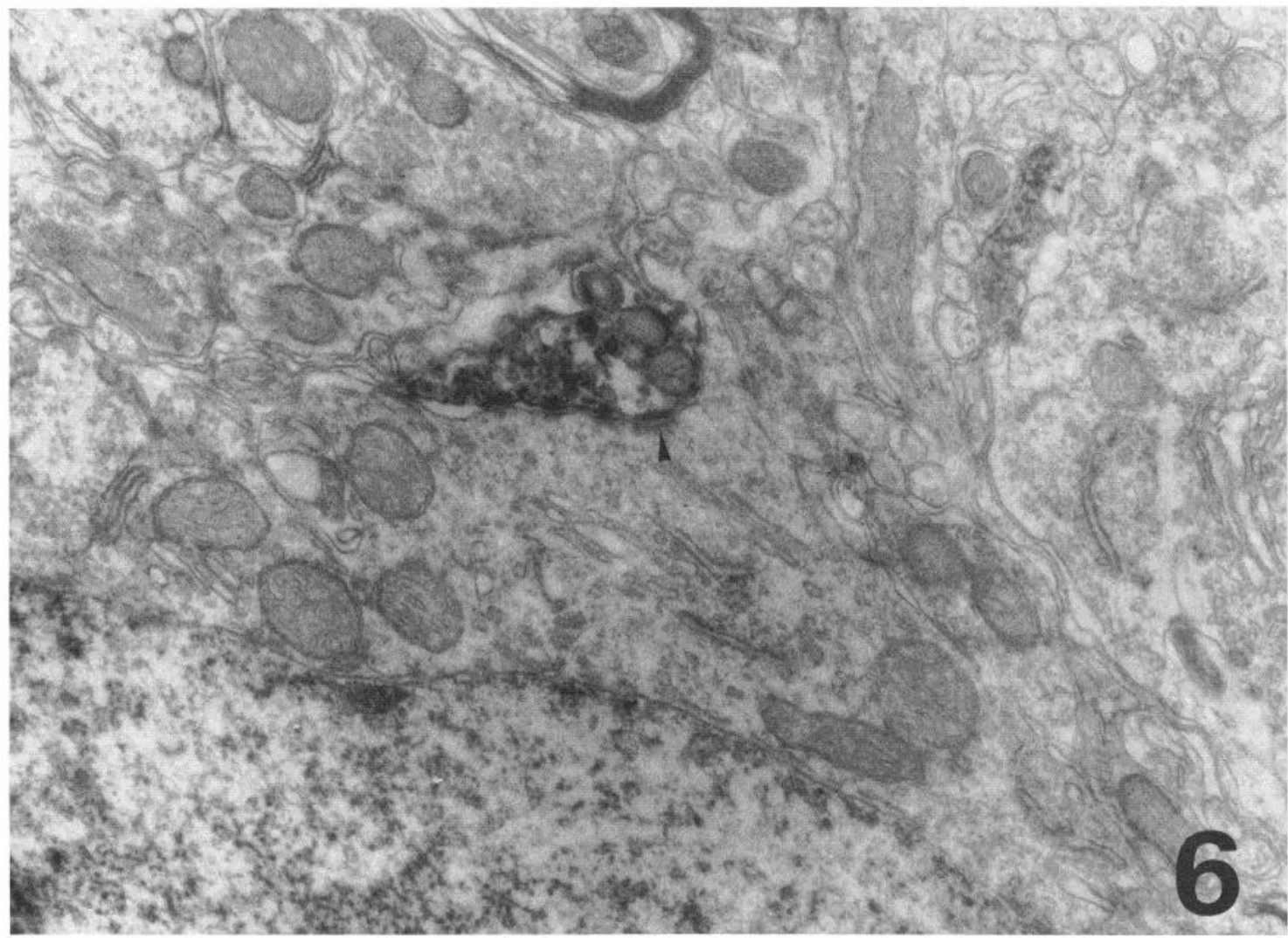

Figure 6. Electron micrograph of CCKI terminals which make synaptic contact with soma of the vm neurons. In the CCKI terminal, an aggregation of the synaptic vesicles was seen at the contact membrane, some of which appeared to be fused with the membrane; without lead staining. The arrowhead indicates the zonula adherens. Magnification $\times 37,000$.

stance $\mathrm{P}$, enkephalins, endorphins, luteinizing hormonereleasing hormone, $\mathrm{ACTH}$, or vasoactive intestinal polypeptide. The radioimmunoassay also demonstrated that this antiserum is C-terminal region specific (Hashimura et al., 1982). The specificity of this antiserum was also confirmed by an absorption test. CCK- 8 antiserum pretreated with an excess of CCK-8 $(0.1 \mathrm{mM})$ served as the absorption control serum. Since the structures stained with CCK- 8 antiserum were not seen in the sections incubated with absorbed control serum, these structures were considered specific. Although these materials should correctly be described as showing CCK-8-like or gastrin-like immunoreactivity, we used the simpler term "CCKI."

\section{Nomenclature}

Nomenclature followed that of König and Klippel (1963), Palkovits and Jacobowitz (1974), and van Houten and Brawer (1978).

\section{Results}

\section{Light microscopic analysis}

Distribution of CCKI structures in the vm. As shown in Figure 2, CCKI fibers were unevenly distributed throughout the entire rostrocaudal extent of the vm. They were moderately concentrated in the ventrolateral area but decreased in number toward the dorsomedial portion. The CCKI fiber plexus was composed of very fine terminals (Fig. 4e). No CCKI cells were detected, even in the colchicine-treated rats.

Knife cut experiment. Hemitransection of the brain caudal to the vm (A $3430 \mu \mathrm{m}$ ) caused a marked ipsilateral decrease in CCKI fibers in the vm, whereas hemi- or total transection just rostrally (A $5660 \mu \mathrm{m}$ ) did not. Hemitransection of the brain just rostral to pbd (A 160 $\mu \mathrm{m})$ resulted in a similar decrease, whereas hemi- or total transection just caudal to the pbd (P $2000 \mu \mathrm{m}$ ) did not. Thus, the majority of CCKI fibers in the vm appear to originate in the area between A $160 \mu \mathrm{m}$ and P $2000 \mu \mathrm{m}$. Within this area, CCKI cell groups were found in the lateral part of the pbd (Figs. 3 and $4 c$ ), colliculus inferior, dorsal nucleus of the lateral lemniscus, the most caudal part of the nucleus raphe dorsalis, and central gray matter of the colchicine-treated rats.

HRP experiment. Based on the results of the knife cut study, HRP was injected iontophoretically into the vm (Fig. 5a), and the locations of HRP-labeled cells found in the area between A $160 \mu \mathrm{m}$ and P $2000 \mu \mathrm{m}$ were compared with those of CCKI cells in the same area. The location of the labeled cells identified in this area in the cases in which the injection site was restricted to within $\mathrm{vm}$ but did not extend to the areas outside the vm is schematically drawn in Figure 3 (triangles). HRP injection into the areas rostral or dorsal to the vm failed to label these cells. Groups of cells which contained both HRP-labeled cells and CCKI cells were observed in the lateral part of the pbd (Figs. 3 and $4, b$ and $c$ ), central 
gray matter, and inferior colliculus (Fig. 3), where they showed a similar distribution pattern.

Lesion experiments. In cases PB 12, 18, 19, and 29, lesions made in the lateral portion of the pbd (Fig. $4 d$ ) slightly affected the adjacent areas, such as the medial parts of the lemniscus lateralis and pbd, and caused a marked decrease in CCKI fibers in the ipsilateral vm (Fig. 4e), as was also seen upon transection of the brain just caudal to the vm or rostral to the pbd. In cases PB $13,14,21,24$, and 25 , lesions centered adjacent to and partially including the lateral portion of the pbd caused a moderate reduction of CCKI fibers in the vm. However, lesions made in the medial portion of the pbd or its adjacent areas, with the lateral part of the pbd intact, as well as those made in the central gray matter or inferior colliculus, caused no reduction of CCKI fibers in the vm. These findings suggest that the majority of CCKI fibers in the vm are supplied by CCKI neurons in the lateral part of the pbd.

\section{Electron microscopic analysis}

General observations of CCKI terminals in the vm. Fine structures of CCKI fibers in the vm were examined mainly in the ventrolateral part, because the fibers were concentrated in this area (Figs. 2 and $4 e$ ). The labeled terminals were easily identified under electron microscopy due to the electron-dense precipitates. In these terminals (diameter about 0.4 to $1.8 \mu \mathrm{m}$ ), immunoreactive end products were associated with the surface membrane of the cell's organelles, such as small lucent synaptic vesicles, mitochondria, and the inner surface of the cell membrane (Figs. 5 to 8 ).

Synaptic contact. More than 200 micrographs of well preserved CCKI terminals photographed at random were examined to determine the relationship between labeled and unlabeled neuronal components.

Immunoreactive terminals generally made synaptic contacts with both the soma and dendrites that were devoid of immunoreactivity.

Axosomatic contact. Numerous CCKI terminals were seen around the vm neurons. They showed a direct apposition to the soma (Figs. 5, 6, and 7a). Since an aggregation of synaptic vesicles to the contact membrane in the CCKI terminals (Figs. 6 and $7 a$ ) and a slight amount of electron-dense materials were seen where an aggregation of the vesicles are identified, these terminals appeared to form symmetrical synapses with soma. Moreover, CCKI formed axospinous contact (Fig. $7 b$ ). However, in this case, a typical asymmetrical synapse was observed (Gray, 1959). In addition to these contacts, electron-dense substances were often seen between the CCKI terminals and soma (Fig. 6, arrowhead). They appeared to belong to the zonula adherens, because no aggregation of the synaptic vesicles was detected where electron-dense substances are found.

The neuronal soma in contact with CCKI terminals had moderately electron-lucent cytoplasm with large nuclei that varied in shape and were often invaginated (Fig. $5 a$ ). Chromatin aggregates in the karyoplasm formed a faint rim around the nucleolus (Figs. 5 and 6). The organelles were dispersed throughout the electron-lucent matrix (Fig. 7a). The majority of the ribosomes appears as unbounded rossetes that were unevenly distributed in the cytoplasm. The granular endoplasmic reticulum often appeared as short segments but not as aggregated Nissl substance. Well developed Golgi apparatus were found throughout the cytoplasm. Large alveolate vesicles and small vesicles were often associated with a Golgi complex (Fig. 5b). The chromatoid body (Millhouse, 1978) or cytoplasmic filamentous body (van Houten and Brawer, 1978) was frequently found in these neuronal perikarya.

Axodendritic contact. The CCKI terminals also made contact with moderately large ( 0.4 to $1.6 \mu \mathrm{m}$ in diameter) dendrites that contained numerous cytoplasmic organelles, such as membranous structures, free ribosomes, and microtubules. Both symmetrical (Fig. 8a) and asymmetrical (Fig. 8b) synapses were seen. In addition, CCKI terminals made zonula adherens with the dendrites as seen in the soma (Fig. $8 c$ ). The dendrites that received CCKI terminals often projected to closely lying soma.

Axoaxonic contact. Distinct axoaxonic contact was not observed in this area, although immunoreactive axon
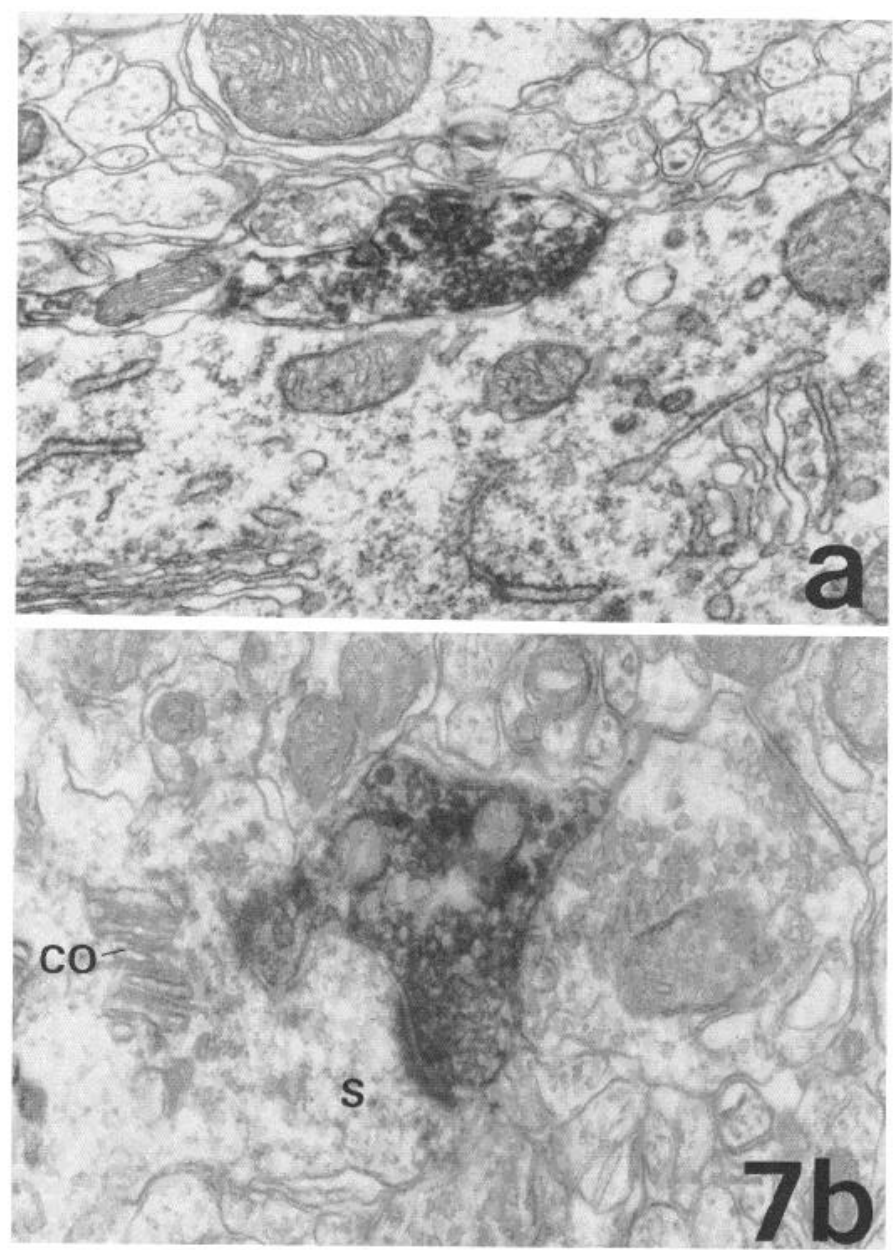

Figure 7. a, Electron micrograph showing axosomatic contact between CCKI terminals and soma of the vm neuron; without lead staining. $b$, Electron micrograph of CCKI terminal which show typical asymmetrical axospinous synapse; without lead staining. $C O$, cisternal organelle; $S$, spine. Magnification: $a$, $\times 31,000 ; b, \times 37,000$. 

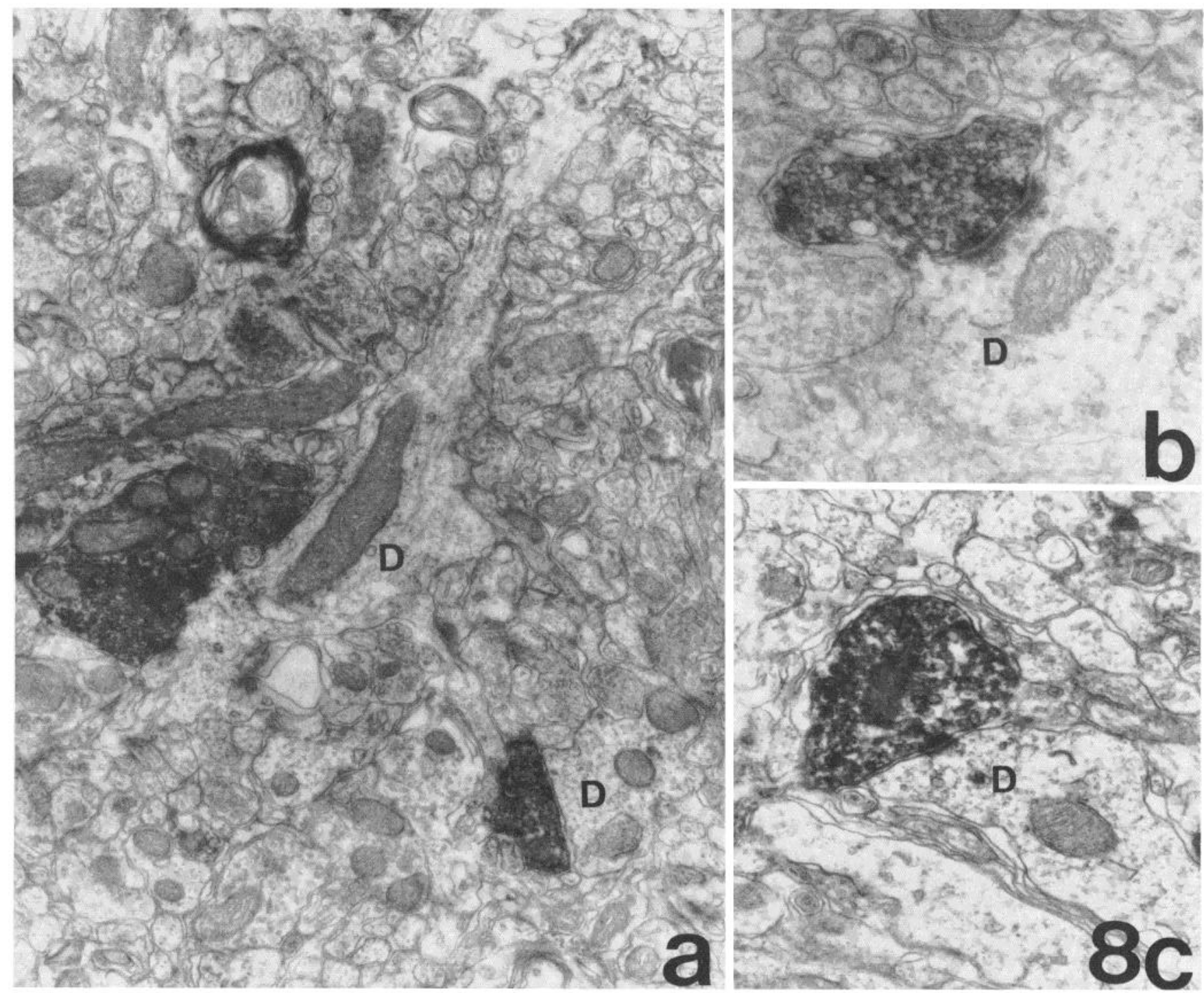

Figure 8. Electron micrographs showing axodendritic contact of CCKI terminals with the dendrite $(D)$. CCKI terminals make both symmetrical $(a)$ and asymmetrical $(b)$ synapses with the dendrites. Note that these dendrites were relatively large in size and contained cytoplasmic organelles. CCKI terminals often form zonula adherens with the dendrite. Note that no aggregation of synaptic vesicles was seen in the terminals just beneath the contact membrane. $a$ and $c$, with lead staining; $b$, without lead staining. Magnifications: $a, \times 24,000 ; b, \times 42,000 ; c, \times 32,000$.

terminals were often situated in close apposition to other axon terminals that lacked immunoreactivity.

\section{Discussion}

The present experimental immunohistochemical study demonstrated that CCKI terminals in the vm originate from CCKI cells in the lateral part of the pbd. Using a tracer technique, McBride and Sutin (1977) and Saper and Loewy (1980) demonstrated the presence of a pbdvm tract (see also Edley and Graybiel, 1983). Based upon our findings, it is probable that CCK is one of the major components of the pbd-vm tract.

The parabrachial area is well known as the pontine gustatory center (Norgren, 1974, 1976). However, the location of this center appears to be different from that of the CCKI cells in the parabrachial area; the former area is located more caudoventrally than the CCKI cells in the pbd. Thus, it seems unlikely that the vm receives the input monosynaptically from the gustatory center via CCK, although it is possible that CCKI neurons in the lateral portion of the pbd, which project to the vm, receive inputs from the gustatory center.

Our electron microscopic experiments revealed that CCKI terminals in the vm make synaptic contact with neuronal soma or proximal segments of the dendrites of the nonlabeled cells. These soma have moderately electron-lucent cytoplasm and may belong to the "common cells" defined by Millhouse (1978), because such cells exhibit a less electron-dense matrix and fewer Nissl bodies than uncommon cells.

The dendrites that receive CCKI inputs appear to be proximal segments of the dendrites of the neuronal cells mentioned above, because they contain numerous cytoplasmic organelles and could often be traced to the soma whose cytoplasmic characteristics are very similar to those with which CCKI terminals make contact.

Hendry et al. (1983) and Palkovits et al. (1982) showed that CCKI terminals make symmetrical synapses in the 
cerebral cortex and solitary nucleus. The present study, also involving the vm, confirmed the presence of symmetrical CCKI synapses and further found that CCKI terminals make asymmetrical synapses with spines and dendrites.

Pharmacological studies suggest that CCK might be related to the feeding function (Koopmans et al., 1972; Gibbs et al., 1973a, b; Antin et al., 1975, 1978; Leibling et al., 1975; Smith and Gibbs, 1975; Berstein et al., 1976; Sturdevant and Goetz, 1976; Maddison, 1977; Mueller and Hsiao, 1977; Houpt et al., 1978; Mineka and Snowdon, 1978; Nemeroff et al., 1978; Della Fera and Baile, 1979; Felasco et al., 1979; Stacher et al., 1979; McLaughlin and Baile, 1980; Parrott and Batt, 1980; Crawley et al., 1981; Della-Fera et al., 1981; Kissileff et al., 1981; Myers and McCaleb, 1981; Parrott and Baldwin, 1981; Smith et al., 1981). On the other hand, it is well established that the vm plays a role in appetite (Hobel and Teitebaum, 1962; Brobeck, 1964; Palka and Sawer, 1966; Bernardi and Skelton, 1967; Mayer and Thomas, 1967; Stevenson, 1969; Palka et al., 1971; Carrer et al., 1973/74; Grossman, 1975; Nance, 1976; Novin et al., 1976; Oomura, 1976).

Furthermore, the microinjection of the chemical analogue of the CCK, caerulein, into the rat vm suppresses feeding (Stern et al., 1976). Although the present findings imply that CCKI cells in the lateral part of the pbd directly influence vm cells ("common cells"), further studies are needed to clarify the relationship between CCK and vm functions.

Note added in proof. After submission of this paper, an abstract was published by Záborsky et al. ((1983) Soc. Neurosci. Abstr. 9: 453) suggesting a CCK projection from the parabrachial nucleus to the vm.

\section{References}

Antin, J., J. Gibbs, J. Holt, R. C. Young, and G. P. Smith (1975) Cholecystokinin elicits the complete behavioral sequence of satiety in rats. J. Comp. Physiol. Psychol. 89: 784790.

Antin, J., J. Gibbs, and G. P. Smith (1978) Cholecystokinin interacts with pregastric food stimulation to elicit satiety in the rat. Physiol. Behav. 20:67-70.

Beinfeld, M. C., and M. Palkovits (1982) Distribution of cholecystokinin (CCK) in the rat lower brain stem nuclei. Brain Res. 238: 260-265.

Bernardi, L. L., and L. A. Frohman (1971) Effect of hypothalamic lesion at different loci on development of hyperinsulinemia and obesity in the weanling rat. J. Comp. Neurol. 141: 107-118.

Bernardi, L. L., and F. R. Skelton (1967) Growth and obesity in male rat after placement of ventromedial hypothalamic lesion at four different ages. J. Endocrinol. 38: 351-352.

Berstein, I. L., E. C. Lotter, and J. C. Zimmerman (1976) Cholecystokinin-induced satiety in weanling rats. Physiol. Behav. 17: 541-543.

Bray, G. A., and L. A. Campfield (1975) Metabolic factors in the control of energy stores. Metabolism 24: 99-117.

Brobeck, J. R. (1946) Mechanism of the development of obesity in animals with hypothalamic lesions. Physiol. Rev. 26: 541549.

Carrer, H. G., G. Asch, and C. Aron (1973/74) New facts concerning the role played by the ventromedial nucleus in control of estrus cycle duration and sexual receptivity in the rat. Neuroendocrinology 13: 129-138.

Cho, H. J., Y. Shiotani, S. Shiosaka, S. Inagaki, Y. Kubota, H. Kiyama, K. Umegaki, K. Tateishi, E. Hashimura, T. Hamaoka, and M. Tohyama (1983) Ontogeny of cholecystokinin-8-containing neuron system of the rat: An immunohistochemical analysis. I. Forebrain and upper brain stem. J. Comp. Neurol. 218: 25-41.

Coons, A. H. (1958) Fluorescent antibody methods. In General Cytochemical Methods, J. F. Danielli, ed., pp. 399-422, Academic Press, New York.

Crawley, J. N., S. E. Hays, S. M. Paul, and F. K. Goodwin (1981) Cholecystokinin reduces exploratory behavior in mice. Physiol. Behav. 27: 407-411.

Della-Fera, M. A., and C. A. Baile (1979) Cholecystokinin octapeptide-containing picomole injections into the cerebral ventricles of sheep suppress feeding. Science 206: 471-473.

Della-Fera, M. A., C. A. Baile, B. S. Schneider, and J. A. Grinker (1981) Cholecystokinin antibody injected in cerebral ventricles stimulates feeding in sheep. Science 212:687-689.

Dockray, G. J. (1976) Immunohistochemical evidence of cholecystokinin-like peptides in the brain. Nature (Lond.) 264: $568-570$.

Dockray, G. J., R. A. Gregory, and J. B. Huthinson (1978) Isolation, structure and biological activity of two cholecystokinin octapeptides from sheep brain. Nature (Lond.) 274: 711-713.

Edley, S. M., and A. N. Graybiel (1983) The afferent and efferent connections of the feline nucleus tegmenti pedunculopontis, pars compacta. J. Comp. Neurol. 217: 216-226.

Emson, P. C., C. M. Lee, and J. F. Rehfeld (1980) Cholecystokinin octapeptide: Vesicle localization and Ca-dependent release from rat brain in vitro. Life Sci. 16: 2157-2163.

Falasco, J. D., G. P. Smith, and J. Gibbs (1979) Cholycystokinin suppresses sham feeding in the rhesus monkey. Physiol. Behav. 23: 887-890.

Gibbs, J., R. C. Young, and G. P. Smith (1973a) Cholecystokinin decreases food intake in rats. J. Comp. Physiol. Psychol. 84: 488-495.

Gibbs, J., R. C. Young, and G. P. Smith (1973b) Cholecystokinin elicits satiety in rats with open gastric fistulas. Nature (Lond.) 245: 323-325.

Gray, E. G. (1959) Axo-somatic and axo-dendritic synapses of the cerebral cortex: An electron microscope study. J. Anat. 93: 420-433.

Greenwood, R. S., S. E. Godae, T. A. Reaves, Jr., and J. N. Hayward (1981) Cholecystokinin in hippocampal pathways. J. Comp. Neurol. 203: 335-350.

Grossman, S. P. (1975) Role of the hypothalamus in the regulation of food and water intake. Psychol. Rev. 82: 200-224.

Handelmamm, G., D. K. Meyer, M. C. Beinfeld, and W. H. Ortel (1982) CCK-containing terminals in the hippocampus are derived from intrinsic neurons: $\Lambda \mathrm{n}$ immunohistochemical and radioimmunological study. Brain Res. 224: 180-184.

Hashimura, E., F. Shimizu, T. Nishimoto, K. Imagawa, K. Tateishi, and T. Hamaoka (1982) Production of rabbit antibody specific for amino-terminal residues of cholecystokinin octapeptide (CCK-8) by selective suppression of crossreactive antibody response. J. Immunol. Methods 55: 375-387.

Hendry, S. H. C., E. G. Jones, and M. C. Beinfeld (1983) Cholecystokinin-immunoreactive neurons in rat and monkey cerebral cortex make symmetrical synapse and have intimate associations with blood vessels. Proc. Natl. Acad. Sci. U. S. A. $80: 2400-2404$.

Hetherington, A. W., and S. W. Ranson (1940) Hypothalamic lesions and asiposity in the rat. Brain Res. 13: 284-297.

Hetherington, A. W., and S. W. Ranson (1942) The spontaneous activity and food intake of rats with hypothalamic lesion. Am. J. Physiol. 136: 609-617. 
Hinman, D. J., and D. R. Griffin (1973) Effects of ventromedial hypothalamic lesions on thyroid secretion rate in rats. Horm. Metab. Res. 5: 48-50.

Hobel, B. G., and P. Teitebaum (1962) Hypothalamic control of feeding and self-stimulation. Science 135: 375-376.

Hökfelt, T., R. Elde, K. Fuxe, O. Johansson, A. Ljungdahl, M. Goldstein, R. Luft, S. Efendic, G. Nilsson, L. Terenius, D. Ganten, S. L. Jeffcoate, J. Rehfeld, S. Said, M. Perez de la Mora, R. Tapia, L. Teran, and R. Palacios (1978) Aminergic and peptidergic pathways in the nervous system with special reference to the hypothalamus. In The Hypothalamus, $\mathrm{S}$. Reichlin, R. J. Rehfeld, and J. B. Matin, eds., pp. 69-135, Raven Press, New York.

Hökfelt, T., J. Rehfeld, L. Skirboll, B. Ivemark, M. Goldstein, and K. Markey (1980a) Evidence for coexistence of dopamine and CCK in the meso-limbic neurons. Nature (Lond.) 285 : $476-478$.

Hökfelt, T., L. Skirboll, J. F. Rehfeld, M. Goldstein, K. Markey, and O. Dann (1980b) A subpopulation of mesencephalic dopamine neurons projecting to limbic areas containing cholecystokinin-like peptide: Evidence from immunohistochemistry combined with retrograde tracing. Neuroscience 5: 2093-2124.

Houpt, T. R., S. M. Anika, and N. C. Wolff (1978) Satiety effect of cholecystokinin and caerulein in rabbit. Am. J. Physiol. 235: R23-R28.

Hsiao, S., C. H. Wang, and T. Schallert (1979) Cholecystokinin, meal pattern, and the intermeal interval: Can eating be stopped before it starts? Physiol. Behav. 23: 909-914.

Innis, R. B., F. M. A. Correa, G. R. Uhl, B. Schneider, and S. H. Snyder (1979) Cholecystokinin octapeptide-like immunoreactivity: Histochemical localization in rat brain. Proc. Natl. Acad. Sci. U. S. A. 76: 521-525.

Kennedy, G. C. (1963) Hypothalamic control of energy balance and reproductive cycle in the rat. J. Physiol. (Lond.) 166: 395-407.

Kissileff, H. R., F. X. Pi-Sunyer, J. Thornton, and G. P. Smith (1981) C-terminal octapeptide of cholecystokinin decreases food intake in man. Am. J. Clin. Nutr. 34: 154-160.

Kiyama, H., S. Shiosaka, Y. Kubota, H. J. Cho, H. Takagi, K. Tateishi, E. Hashimura, T. Hamaoka, and M. Tohyama (1983) Ontogeny of cholecystokinin-8 containing neuron sys tem of the rat: An immunohistochemical analysis. II. Lower brain stem. Neuroscience 10: 1341-1360.

König, J. F. R., and R. A. Klippel (1963) The Rat Brain. A Stereotaxic Atlas of the Forebrain and Lower Parts of Brain Stem, Williams \& Wilkins, Baltimore.

Koopmans, H. S., J. A. Deutch, and P. J. Branson (1972) The effect of cholecystokinin-pancreozymin on hunger and thirst in mice. Behav. Biol. 7: 441-444.

Kubota, Y., S. Inagaki, S. Shiosaka, H. J. Cho, K. Tateishi, E. Hashimura, T. Hamaoka, and M. Tohyama (1983) The distribution of cholecystokinin octapeptide-like structures in the lower brain stem of the rat: An immunohistochemical analysis. Neuroscience 9: 587-604.

Larsson, L. I., and J. F. Rehfeld (1979) Location and molecular heterogeneity of cholecystokinin in the central and peripheral nervous system. Brain Res. 165: 201-218.

Leibling, D. S., J. D. Eister, J. Gibbs, and G. P. Smith (1975) Intestinal satiety in rats. J. Comp. Physiol. Psychol. 89: 955965.

Lorén, I., R. Alumets, R. Håkanson, and F. Sundler (1979) Distribution of gastrin and CCK-like peptides. Histochemistry 59: $249-257$.

Maddision, S. (1977) Intraperitoneal and intracranial cholecystokinin depress operant responding for food. Physiol. Behav. 19: 819-924.

Martin, J. B. (1973) Neuronal regulation of growth hormone secretion. N. Engl. J. Med. 288: 1384-1393.

Mayer, J., and D. W. Thomas (1967) Regulation of food intake and obesity. Science 156: 328-337.

McBride, R. L., and J. Sutin (1977) Amygdaloid and pontine projections to the ventromedial nucleus of hypothalamus. J. Comp. Neurol. 174: 377-396.

McLaughlin, C., and C. A. Baile (1980) Decreased sensitivity of Zuker obese rats to the putative agent cholecystokinin. Physiol. Behav, 25: 543-548.

Mesulam, M. M. (1978) Tetramethylbenzidine for horseradish peroxidase neurohistochemistry: A noncarcinogenic blue reaction product with superior sensitivity for visualizing afferents and efferents. J. Histochem. 26: 106-117.

Meyer, D. K., M. C. Beinfeld, W. H. Oertel, and M. J. Brownstein (1981) Origins of the cholecystokinin-containing fibers in the rat caudoputamen. Science 215: 187-188.

Millhouse, O. E. (1978) Cytological observations on ventromedial hypothalamic nucleus. Cell Tissue Res. 191: 473-491.

Mineka, S., and C. T. Snowdon (1978) Inconsistency and possible habituation of CCK induced satiety. Physiol. Behav. 21: $65-72$.

Mueller, K., and S. Hsiao (1977) Specificity of cholecystokinin satiety effect: Reduction of food but not water intake. Pharmacol. Behav. 6: 643-646.

Muller, J. E., E. Straus, and R. S. Yalow (1967) Cholecystokinin and its $\mathrm{COOH}$-terminal octapeptide in the pig brain. Proc. Natl. Acad. Sci. U. S. A. 74: 3035-3037.

Myers, R. D., and M. D. McCaleb (1981) Peripheral and intrahypothalamic cholecystokinin act on the noradrenergic "feeding circuit" in the rat's diencephalon. Neuroscience 6 : $645-655$.

Nance, D. W. (1976) Sex differences in the hypothalamic regulation of feeding behavior in the rat. Adv. Psychobiol. 3 : $75-123$.

Nemeroff, C. B., A. J. Osbahr, G. Bissette, G. Jahnke, M. Lipton, and A. J. Prange, Jr. (1978) Cholecystokinin inhibits tail pinch-induced eating in rats. Science 200: 17-30.

Norgren, R. (1974) Gustatory afferents to ventral forebrain. Brain Res. 67: 219-238.

Norgren, R. (1976) Taste pathways to hypothalamus and amygdala. J. Comp. Neurol. 166: 17-30.

Novin, D., W. Wyrwicka, and G. Bray (1976) Hunger--Basic Mechanisms and Clinical Implications, Raven Press, New York.

Noyer, M., N. D. Bui, M. Deschodt-Lackman, P. Robberecht, M. C. Woussen, and J. Christophe (1980) Postnatal development of the cholecystokinin family of peptides in the brain and gut of the rat. Life Sci. 27: 2197-2203.

Oomura, Y. (1976) Significance of glucose, insulin, and free fatty acid on the hypothalamic and satiety neurons. In Hunger-Basic Mechanisms and Clinical Implications, D. Novin, W. Wyrwicka, and G. Bray, eds., pp. 145-157, Raven Press, New York.

Palka, Y. S., and C. H. Sawer (1966) Induction of estrous behavior in rabbits by hypothalamic implants of testosterone. Am. J. Physiol. 211: 225-228.

Palka, Y. S., R. A. Leibert, and V. Critchlow (1971) Obesity and increased growth following partial or complete isolation of ventromedial hypothalamus. Physiol. Behav. 7: 187-194.

Palkovits, M., and D. M. Jacobowitz (1974) Topographic atlas of catecholamine and acethylcholinesterase-containing neurons in the rat brain. II. Hindbrain (mesencephalon, rhombencephalon). J. Comp. Neurol. 157: 29-42.

Palkovits, M., J. Z. Kiss, M. C. Beinfeld, and T. H. Williams (1982) Cholecystokinin in the nucleus of the solitary tract of the rat: Evidence for its vagal origins. Brain Res. 252: 386390.

Parrott, R. F., and B. A. Baldwin (1981) Operant feeding and 
drinking in pig following intracerebro-ventricular injection of synthetic cholecystokinin octapeptide. Physiol. Behav. 26: $419-422$.

Parrott, R. F., and R. A. L. Batt (1980) The feeding response of obese mice (genotype, $o b o b$ ) and their wild-type littermates to cholecystokinin (pancreozymin). Physiol. Behav. 24: 751-753.

Pinget, M., E. Straus, and E. Yalow (1979) Release of cholecystokinin from a synaptosome-enriched fraction of rat cerebral cortex. Life Sci. 25: 339-342.

Rehfeld, J. F. (1977) Cholecystokinin and gastrin in brain and gut. Acta Pharmacol. Toxicol. 41(Suppl. 4): 24.

Rehfeld, J. F. (1978a) Immunochemical studies on cholecystokinin. I. Development of sequence specific radioimmunoassay for porcine tricontapeptide cholecystokinin. J. Biol. Chem. 253: 4016-4021.

Rehfeld, J. F. (1978b) Immunochenical studies on cholecystokinin. II. Distribution and molecular heterogeneity in the central nervous system and small intestine of man and hog. J. Biol. Chem. 253: 4016-4021.

Rehfeld, J. F. (1980) Cholecystokinin. Trends Neurosci. 3: 6567.

Rehfeld, J. F., and N. Goltermann (1979) Immunochemical evidence for cholecystokinin tetra-peptides in hog brain. J. Neurochem. 32: 1339-1341.

Rehfeld, J. F., N. Golterman, L. I. Larsson, P. C. Emson, and C. M. Lee (1979) Gastrin and cholecystokinin in central and peripheral neurons. Fed. Proc. 38: 2325-2329.

Ridley, P. T., and F. P. Brooks (1965) Gastric secretion following hypothalamic lesions producing hyperphagia. Am. J. Physiol. 209: 319-323.

Roberts, G. W., P. L. Woofhams, J. M. Polak, and T. J. Crow (1982) Distribution of neuropeptides in the limbic systems of the rat: The amygdaloid complex. Neuroscience 7: 99-131.

Saper, C. B., and A. D. Loewy (1980) Efferent connections of the parabrachial nucleus in the rat. Brain Res. 197: 291-317.

Sawer, C. H. (1957) Triggering of the pituitary by the central nervous system. In Physiological Triggers, T. H. Bullock, ed., p. 164, American Physiological Society, Bethesda, MD.

Smith, G. P., and J. Gibbs (1975) Cholecystokinin: A putative satiety signal. Central Neural Control Eating Obesity 3(Suppl. 1): 135-138.

Smith, G. P., C. Jerme, B. J. Cushin, R. Eterno, and K. J. Simansky (1981) Abdominal vagotomy blocks the satiety effect of cholecystokinin in the rat. Science 213: 1036-1037.

Somogyi, P., and H. Takagi (1982) A note on the use of picric acid-paraformaldehyde-glutaraldehyde fixative for correlated light and electron microscopic immunocytochemistry. Neuroscience 7: 1779-1784.

Sornogyi, P., J. V. Priestley, A. C. Cuello, A. D. Smith, and J. P. Bolam (1982) Synaptic connections of substance P-immunoreactive nerve terminals in the substantia nigra of the rat: A correlated light- and electron-microscopic study. Cell Tissue Res. 223: 469-486.
Stacher, G., J. Bauer, and H. Steinringer (1979) Cholecystokinin decreases appetite and activation evoked by stimuli arising from the preparation of a meal in man. Physiol. Behav. 23: $325-331$.

Stern, J. J., C. A. Cudilli, and J. Kruper (1976) Ventromedial hypothalamus and short term feeding suppression by caerulein in male rats. J. Comp. Physiol. Psychol. 90: 484-490.

Sternberger, L. A., P. H. Hardy, J. J. Curculis, and H. G. Meyer (1970) The unlabelled antibody-enzyme method of immunocytochemistry. Preparation and properties of soluble antigen-antibody complex (horseradish peroxidase) and its use in identification of spirochetes. J. Histochem. Cytochem. 18: 315-333.

Stevenson, J. A. F. (1969) Neural control of food and water intake. In The Hypothalamus, E. Anderson and W. J. H: Nauta, eds., pp. 524-621, Charles C Thomas, Springfield, IL. Straus, E., J. E. Muller, H. S. Choi, F. Paronetto, and R. S. Yalow (1977) Immunohistochemical localization in rabbit brain of a peptide resembling the $\mathrm{COOH}$-terminal octapeptide of cholecystokinin. Proc. Natl. Acad. Sci. U. S. A. 74: 3033-3034.

Sturdevant, R. A. L., and H. Goetz (1976) Cholecystokinin both stimulates and inhibits food intake. Nature 261: 713-715.

Szentágothai, J., B. Flerko, B. Mess, and B. Halasz (1968) Hypothalamic Control of the Anterior Pituitary. An Experimental Morphologic Study, Ed. 3, Akademie Kiad, Budapest. Takeuchi, M., and Y. Noda (1973) Light and electron microscope studies on the ventromedial hypothalamic nucleus of the cat, with special reference to the fine structures of neurons and synapse. Folia Psychiatr. Neurol. Jpn. 28: 45-63.

Vanderhaeghen, J. J., J. C. Signeau, and W. Gepts (1975) New peptide in the vertebrate CNS releasing with gastrin antibodies. Nature 221: 557-559.

Vanderhaeghen, J. J., F. Lotstra, J. De Mey, and G. Gilles (1980) Immunohistochemical localization of cholecystokininand gastrin-like peptides in the brain and hypophysis of the rat. Proc. Natl. Acad. Sci. U. S. A. 77: 1190-1194.

Vanderhaeghen, J. J., F. Lotstram, F. Vandesande, and K. Dierickx (1981) Coexistence of cholecystokinin and oxytocinneurophysin in some magnocellular hypothalamo-hypophyseal neurons. Cell Tissue Res. 221: 227-231.

Vandesande, F., K. Dierickx, and J. De Mey (1977) The origin of the vasopressinergic and oxytocinergic fibers of the external region of the median eminence of the rat hypothalamus. Cell Tissue Res. 180: 443-452.

Van Houten, M., and J. R. Brawer (1978) Cytology of neurons of the hypothalamic ventromedial nucleus in the adult male rat. J. Comp. Neurol. 178: 89-116.

Wheatley, M. D. (1944) Hypothalamus and affective behavior in cats: Study effects of experimental lesions with anatomical correlations. Arch. Neurol. Psychiatry 52: 296-316.

Zamboni, L., and C. De Martino (1967) Buffered picric-acid formaldehyde: A new fixative for electronmicroscopy. J. Cell Biol. 35: 148A. 